\title{
A Prospective Study on the Prevalence and Antibiotic Sensitivity Pattern of Methicillin Resistant Staphylococcus aureus isolated from Various Clinical Specimen at a Tertiary Care Post Graduate Teaching Institute
}

\author{
Anjali Kulshrestha ${ }^{1}$, V. Anamika ${ }^{2}$, K. Mrithunjay ${ }^{2}$, V. Himanshu ${ }^{3}$, \\ K. Manish ${ }^{4}$ and A.S Dalal ${ }^{2}$ \\ ${ }^{1}$ Department of Microbiology, NIMS, Shobha nagar, Jaipur, Rajasthan, India \\ ${ }^{2}$ Department of Microbiology, GMCH, Udaipur, India \\ ${ }^{3}$ Departmen of Anaesthesia and Critical Care, SRMS-IMS, Bareilly, India \\ ${ }^{4}$ DNB, Apollo, New Delhi, India \\ *Corresponding author: anjalikulshrestha2185@gmail.com
}

\begin{abstract}
A B S T R A C T
In recent times, the treatment of Staphylococcus aureus infection has become problematic because of emergence of resistance to antibiotics which is a cause of concern for all the clinicians and microbiologists worldwide. Infections caused by MRSA have been Keywords associated with high morbidity and mortality rates. Hence this study was conducted to know the prevalence of Methicillin resistant Staphylococcus aureus [MRSA] isolates in various clinical specimens and to determine the sensitivity of these isolates to different antimicrobial agents. Among the 161 clinical isolates of S. aureus, highest isolation was from pus samples (64\%), followed by blood (13\%) and respiratory secretions (13\%). 82 (51\%) were identified as MRSA by Cefoxitin disc diffusion method and maximum MRSA were again isolated from pus $(61 \%)$. Comparatively MRSA prevalence is more in males (73\%) and most common affected age group was 21-30 years. All MRSA strains were resistant to penicillin (100\%), followed by ciprofloxacin $(93 \%)$ and erythromycin $(61 \%)$. We found statistically significant differences in the drug susceptibility pattern of MRSA \& MSSA for Penicillin, Clindamycin, Erythromycin, Ciprofloxacin, Co-trimoxazole and Levofloxacin. MDR-MRSA strains in our study is $45 \%$. Hence we suggest, more and more studies in future are needed to fight against rising menace of antibiotic resistance among Staphylococcus aureus
\end{abstract}

\section{Introduction}

Staphylococcus aureus, the most clinically significant species of Staphylococci has been recognized as an important cause of human disease for more than 100 years (Ankur et al., 2013). It is one of the pathogens of greatest concern because of its intrinsic virulence factors, its ability to cause diverse array of life threatening infections, it's competency to adapt to different environmental conditions and its nasal carriage, which accounts for possible spread and re infection (Anupurba et al., 2003). Infections by Staphylococcus aureus are continuously challenging the clinicians despite the availability of antibiotics from nearly 70 yrs. This was due to the emergence of various types of antibiotic 
resistance mechanisms especially to methicillin and vancomycin, which was the theme of several epidemiological studies (Arora et al., 2010; Assadullah et al., 2003).

With the introduction of Penicillin in 1940, it was thought that we can escape from the deadly threats of Staphylococcal infections, but no sooner in 1944 first strain of Staphylococcus aureus resistant to penicillin $\mathrm{G}$ appeared in London, mediated by the presence of penicillinase enzyme which hydrolyses the $\beta$-lactam ring of penicillin (Astagneau et al., 1996). By 1950s, penicillinase producing strains of Staphylococcus aureus were so common that penicillin became useless against Staphylococcal infections. To resolve this issue, in 1960 semi-synthetic penicillin (penicillinase stable penicillin) - like Methicillin came in picture, but availability of these agents did not stem the tide of resistance as within a year the first MRSA was reported from U.K. This was mediated by the presence of PBP-2a which is expressed by an exogenous gene, mecA (Bandaru, 2010).

In the past few decades MRSA has emerged as an important nosocomial pathogen worldwide. In India, prevalence rate varies from $30-85 \%$ in different parts and has now become endemic (Barber, 1961; Boucher, 2010). A multicentric study done in India involving 17 tertiary care Hospitals reported MRSA prevalence of $41 \%$ in 2008-2009 (Clinical and Laboratory Standards Institute, 2012), MRSA is of serious therapeutic concern not only due to its resistance to Methicillin, but also because of resistance to many other antimicrobials that are used on regular basis in Hospitals. Therefore, the most reliable and sustained therapeutic agent against methicillin-resistant Staphylococcus aureus (MRSA) strains is Vancomycin. Increasing prevalence of MRSA has lead to the extensive use of vancomycin. This inturn has lead to the decreased susceptibility to vancomycin. Such resistance is a serious clinical and public health consequences because currently few licenced alternatives are available to treat vancomycin resistant Staphylococcus aureus infections.

The association of Multidrug resistance with MRSA adds to the problem and the presence of MDR strains in the hospital cannot be neglected. Several studies are prevailing for Methicillin resistance from India but few have worked on Multi-drug resistance. MRSA strain showing resistance towards $\geq 3$ antibiotics is defined as MDR strain and its prevalence ranges from $23 \%-60 \%$ in India (Diep et al.,). The emergence of MDR MRSA infections is worrisome in the present therapeutic scenario. Keeping the above points in view, the present study was planned to find out the prevalence of MRSA among isolates of Staphylococcus aureus in various clinical specimens along with their antibiotic sensitivity pattern so as to guide the clinicians of our hospital to select appropriate antimicrobial agents and also to make them aware, that if inappropriate use these antibiotics is continued it may lead to impending public health disaster.

\section{Materials and Methods}

\section{Source of material}

The present study was conducted in the Department of Microbiology, GMCH, Udaipur, during the year 2013-2014. A total of 161 non- duplicate Staphylococcus aureus isolates from various clinical specimens [pus, wound or vaginal swabs, blood, body fluids (csf, pleural fluid, ascitic fluid) urine, sputum, ET secretion etc] were included in the study. Isolates from both in-patients and out-patients were considered. Institutional Ethical clearance was obtained. Data regarding age, sex, patient location, history of any clinical 
illness etc. was obtained from the requisition form submitted to Microbiology Department, GMCH.

\section{Inclusion criteria}

All Staphylococcus aureus strains isolated from various clinical specimens, were included in the study.

\section{Exclusion criteria}

Clinical specimen's yielding growth of Gram positive cocci other than Staphylococcus aureus and all gram negative bacteria were excluded.

\section{Isolation and identification of Staphylococcus aureus}

All the isolates were identified by standard procedures (gram staining, catalase test, mannitol fermentation, Hugh-Leifson $\mathrm{OF}$ media, slide coagulase and tube coagulase test). Tube coagulase was taken as the main criteria of identification and was performed by diluting plasma in freshly prepared normal saline (1:6). Three to four colonies were emulsified in $1 \mathrm{ml}$ of diluted plasma and the tubes were incubated at $37^{\circ} \mathrm{C}$. Readings were taken at 1, 2, 3 and $4 \mathrm{~h}$ and further incubated at room temperature if no clot formation was observed (Yogesh et al., 2013).

\section{Determination of antibiotic susceptibility}

All Staphylococcus aureus isolates were then subjected to antimicrobial susceptibility testing by modified Kirby-Bauer disc diffusion method. Antibiotics tested were Penicillin [10 units], cefoxitin (30 $\mu \mathrm{g})$,

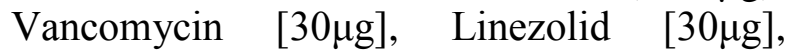
Pristinomycin (Quinupristin/Dalfopristin) $[15 \mu \mathrm{g}], \quad$ Gentamicin $[10 \mu \mathrm{g}], \quad$ Tetracycline [30 $\mu \mathrm{g}]$ Chloramphenicol [30 $\mu \mathrm{g}]$, Ciprofloxacin $[5 \mu \mathrm{g}]$, Levofloxacin $[5 \mu \mathrm{g}]$,

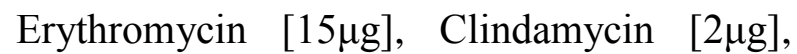

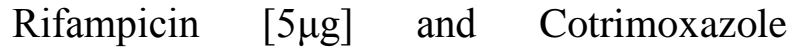

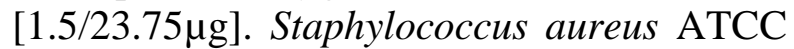
25923 was used as control strain. Zone of inhibition of all the antibiotics were measured with scale in reflected light against a black background, to the nearest $\mathrm{mm}$. Interpretation was done according to the guidelines of Clinical Laboratory Standards Institute.

\section{Detection of methicillin resistance}

Cefoxitin disc (30 $\mu \mathrm{gm})$ was used to detect methicillin resistant isolates as Cefoxitin, which is a potent inducer of the mecA regulatory system, is being widely used as a surrogate marker for detection of mecA genemediated methicillin resistance. MRSA strains exhibiting inducible resistance to methicillin grow much more readily in the presence of cefoxitin than oxacillin, due to an enhanced induction of PBP $2 \mathrm{a}$ by cefoxitin. Isolates with zone diameter of $\leq 21 \mathrm{~mm}$ were considered resistant to methicillin and zone of $\geq 22 \mathrm{~mm}$ were sensitive (Harcharan et al., 2014).

\section{Results and Discussion}

In the present study, a total of 161 non duplicate Staphylococcus aureus isolates were obtained from various clinical specimens. Staphylococcus aureus infection was found comparatively more in Male patients i.e. 115 [71\%] than in female patients 46 [29\%]. The male to female ratio was 2.5:1. Age group of 21-30 yrs and 51-60 yrs were predominantly affected. [Figure 1 and figure 2]. Among all Staphylococcus aureus isolates, majority contribution was from Pus samples 103 (64\%), followed with blood 23(15\%), respiratory secretion $18(11 \%)$ and body fluids 7 (4\%). Swabs and Urine samples grew only $7(4 \%)$ and $3(2 \%)$ respectively.[Table1] Out of total 161 Staphylococcus aureus strains, $82(51 \%)$ were found to be MRSA 
and79 (49\%) were MSSA. Pus shown the highest prevalence of resistance towards methicillin i.e. $(61 \%)$ followed by Blood (15\%), Respiratory secretions (10\%), body fluids (5\%), Swabs (5\%), and Urine (4\%).[ Figure 3, Figure 4 ] Comparatively MRSA prevalence is more in males $(73 \%)$ and most common affected age group was 21-30 years.

Out of 161 Staphylococcus aureus, only 19 (12\%) strains were sensitive to all antibiotics.[Table 2] Maximum resistance was shown by MRSA isolates. All the MRSA isolates were resistant to penicillin (100\%) and all were sensitive to Linezolid, Pristinomycin, Chloramphenicol and Rifampicin. Among the MRSA strains, least sensitivity was showed by Ciprofloxacin (93\%) followed by erythromycin (66\%), Cotrimaxazole (54\%), Levofloxacin (46\%), Clindamycin $(46 \%)$ and Gentamicin $(30 \%)$. Tetracycline (6\%), Vancomycin (3\%) showed good efficacy.

Table.1 Distribution pattern of Staphylococcus aureus isolates in various clinical specimens

\begin{tabular}{|l|c|c|}
\hline \multicolumn{1}{|c|}{ Clinical specimen } & No of isolates & Percentage \\
\hline Pus & 103 & 64 \\
\hline Blood & 23 & 15 \\
\hline Sputum/ ETsecretion / Bronchial aspirate & 18 & 11 \\
\hline Body fluids (csf, pleural fluid, ascitic fluid) & 7 & 4 \\
\hline Swabs ( Vaginal/wound) & 7 & 4 \\
\hline Urine & 3 & 2 \\
\hline Total & $\mathbf{1 6 1}$ & $\mathbf{1 0 0}$ \\
\hline
\end{tabular}

Table.2 Antibiogram of Staphylococcus aureus strains

\begin{tabular}{|l|l|l|l|l|}
\hline \multirow{2}{*}{ Drugs } & \multicolumn{4}{|c|}{ Staphylococcus aureus strains } \\
\cline { 2 - 5 } & Sensitive & \% & Resistant & \% \\
\hline Penicillin G & 19 & 12 & 142 & 88 \\
\hline Cefoxitin & 79 & 49 & 82 & 51 \\
\hline Ciprofloxacin & 54 & 34 & 107 & 66 \\
\hline Levofloxacin & 116 & 72 & 45 & 28 \\
\hline Gentamycin & 136 & 84 & 25 & 16 \\
\hline Erythromycin & 91 & 57 & 70 & 43 \\
\hline Clindamycin & 111 & 69 & 50 & 31 \\
\hline Co-trimaxazole & 91 & 57 & 70 & 43 \\
\hline Tetracycine & 156 & 97 & 5 & 3 \\
\hline Rifampicin & 161 & 100 & 0 & 0 \\
\hline Chloramphenicol & 161 & 100 & 0 & 0 \\
\hline Vancomycin & 156 & 97 & 5 & 3 \\
\hline Linezolid & 161 & 100 & 0 & 0 \\
\hline Quinipristin/dalphopristin & 161 & 100 & 0 & 0 \\
\hline Vanconcin - Accory
\end{tabular}

Vancomycin* - According to CLSI guidelines $2007^{[66]}$ 
Table.3 Antibiogram of MRSA and MSSA

\begin{tabular}{|l|l|l|l|l|}
\hline \multirow{2}{*}{ Drugs } & \multicolumn{2}{|c|}{ MRSA [n=82] } & \multicolumn{2}{c|}{ MSSA [n=79] } \\
\cline { 2 - 5 } & $\begin{array}{l}\text { Sensitive } \\
(\%)\end{array}$ & $\begin{array}{l}\text { Resistance } \\
(\%)\end{array}$ & $\begin{array}{l}\text { Sensitive } \\
(\%)\end{array}$ & $\begin{array}{l}\text { Resistance } \\
(\%)\end{array}$ \\
\hline Penicillin G & $0(0)$ & $82(100)$ & $19(24)$ & $60(76)$ \\
\hline Ciprofloxacin & $6(7)$ & $76(93)$ & $48(61)$ & $31(39)$ \\
\hline Levofloxacin & $44(54)$ & $38(46)$ & $72(91)$ & $7(9)$ \\
\hline Gentamycin & $57(70)$ & $25(30)$ & $79(100)$ & $0(0)$ \\
\hline Erythromycin & $28(34)$ & $54(66)$ & $63(80)$ & $16(20)$ \\
\hline Clindamycin & $44(54)$ & $38(46)$ & $67(85)$ & $12(15)$ \\
\hline Co-trimaxazole & $38(46)$ & $44(54)$ & $53(67)$ & $26(33)$ \\
\hline Tetracycine & $77(94)$ & $5(6)$ & $79(100)$ & $0(0)$ \\
\hline Rifampicin & $82(100)$ & $0(0)$ & $79(100)$ & $0(0)$ \\
\hline Chloramphenicol & $82(100)$ & $0(0)$ & $79(100)$ & $0(0)$ \\
\hline Vancomycin & $82(100)$ & $5(3)$ & $79(100)$ & $0(0)$ \\
\hline Linezolid & $82(100)$ & $0(0)$ & $79(100)$ & $0(0)$ \\
\hline Quinipristin/dalphopristin & $82(100)$ & $0(0)$ & $79(100)$ & $0(0)$ \\
\hline
\end{tabular}

Vancomycin* - According to CLSI guidelines $2007^{[66]}$

Table.4 Statistical analysis of antibiotic resistance pattern of MRSA and MSSA by using software SPSS

\begin{tabular}{|l|l|l|l|l|}
\hline Drugs & $\begin{array}{l}\text { MRSA } \\
\text { Resistance } \\
(\%)\end{array}$ & $\begin{array}{l}\text { MSSA } \\
\text { Resistance } \\
(\%)\end{array}$ & p value & $\begin{array}{l}\text { Statistical } \\
\text { Significance }\end{array}$ \\
\hline Penicillin G & $82(100)$ & $60(76)$ & $<0.001$ & Significant \\
\hline Ciprofloxacin & $76(93)$ & $31(39)$ & $<0.001$ & Significant \\
\hline Levofloxacin & $42(51)$ & $15(19)$ & $<0.001$ & Significant \\
\hline Erythromycin & $50(61)$ & $20(25)$ & $<0.001$ & Significant \\
\hline Clindamycin & $38(46)$ & $10(13)$ & $<0.001$ & Significant \\
\hline Co-trimoxazole & $44(54)$ & $26(33)$ & $<0.001$ & Significant \\
\hline
\end{tabular}

Figure.1 Sex wise distribution of patients with Staphylococcus aureus infection

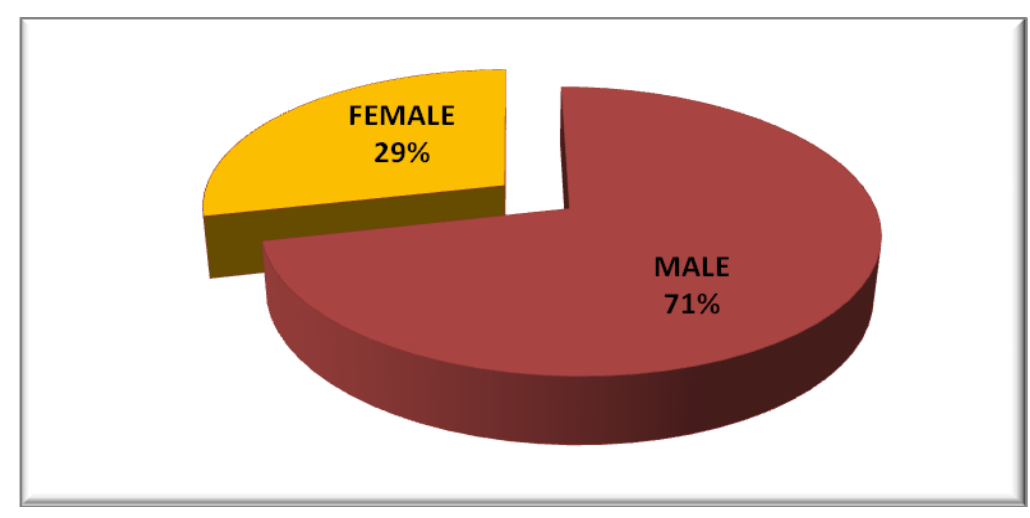


Figure.2 Age wise distribution of patients with Staphylococcus aureus infection

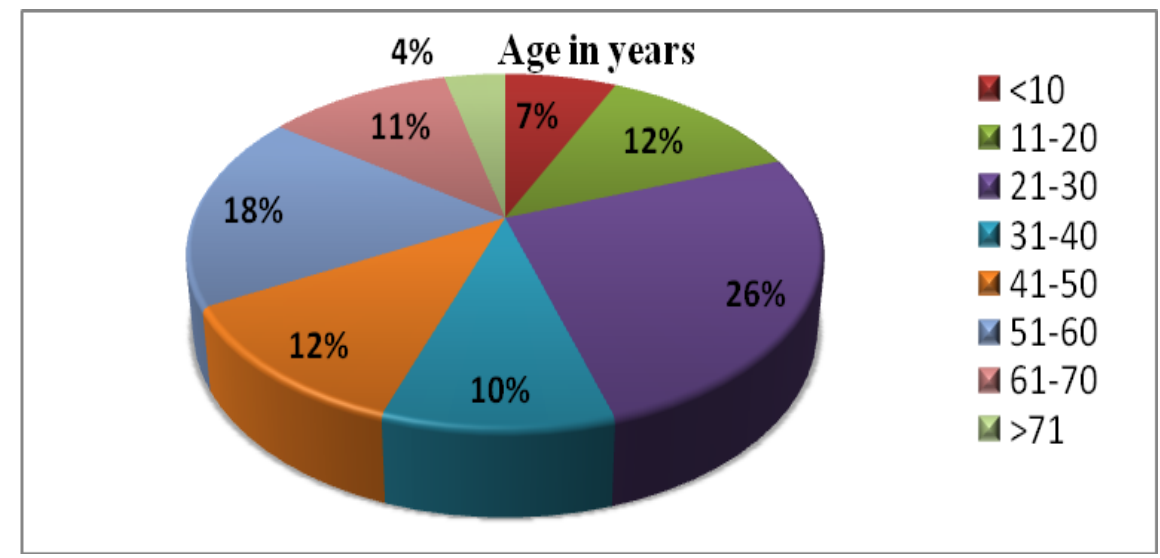

Figure.3 Total number of MRSA and MSSA in Staphylococcus aureus isolates

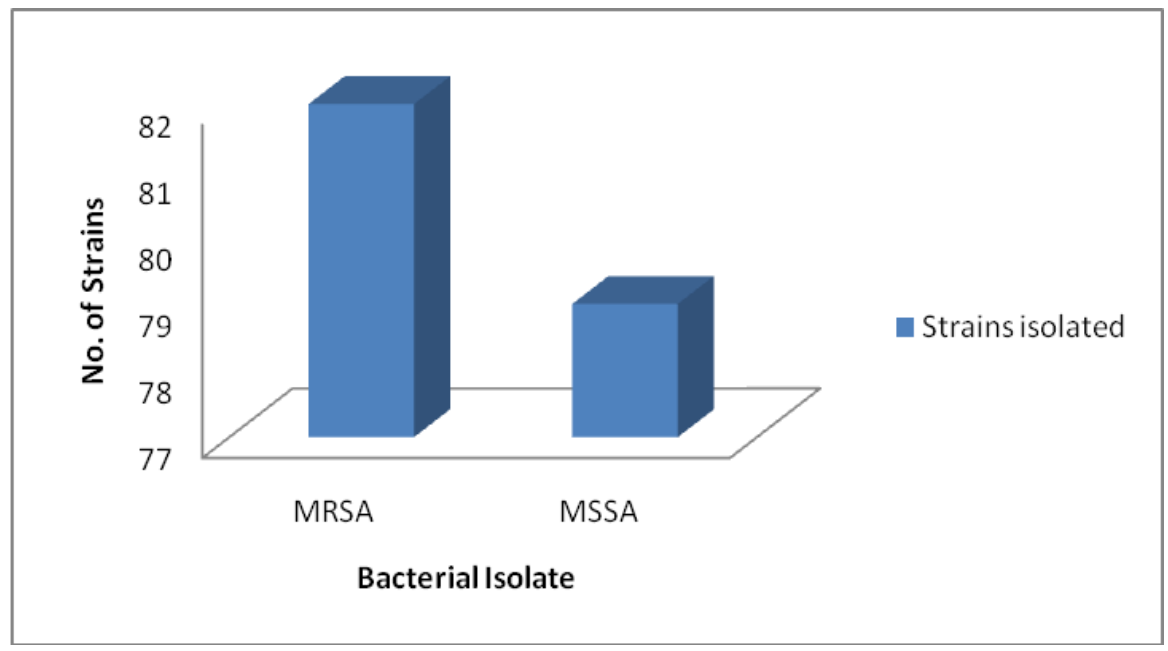

Figure.4 Specimen wise distribution of MSSA

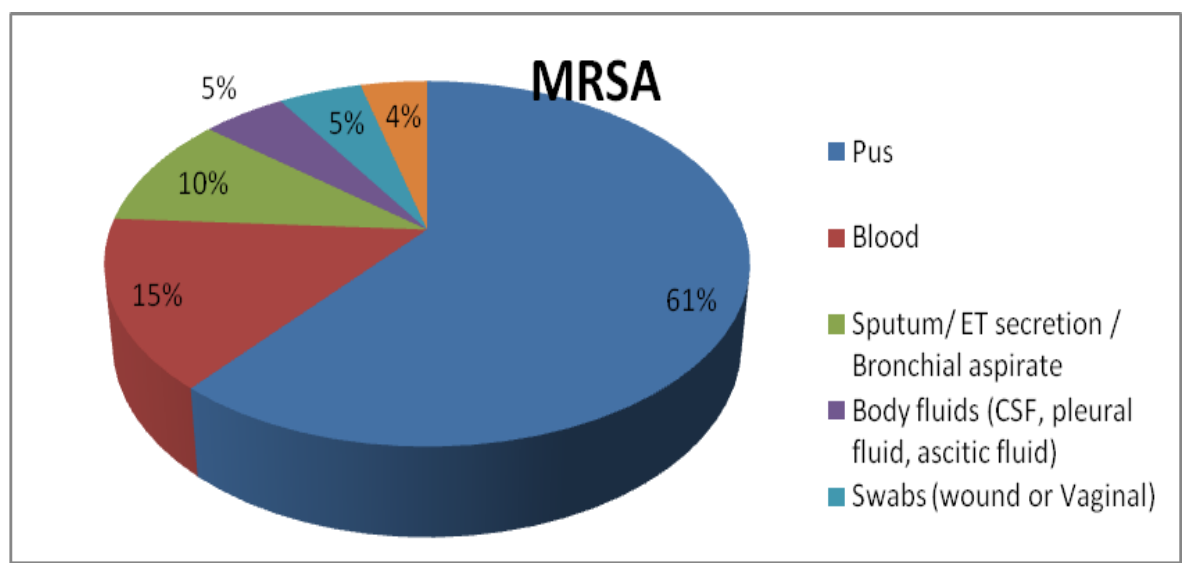


The sensitivity pattern of MSSA was quite different from the MRSA strains. All the MSSA strains showed cent percent sensitivity to Gentamicin, Tetracycline, Vancomycin, Linezolid, Pristinomycin, Chloramphenicol and Rifampicin. Levofloxacin showed the highest sensitivity (91\%) among MSSA strains followed by Clindamycin (85\%), Erythromycin (80\%), Co-trimoxazole $(67 \%)$, Ciprofloxacin (61\%) and showed least sensitivity to penicillin (24\%).(Table 3) Among all above mentioned drugs, antibiotic resistance for MRSA and MSSA was statistically significant only for Pencillin, Clindamycin, Erythromycin, Ciprofloxacin, Co-trimozole and Levofloxacin.(Table 4).

Staphylococcus aureus is a major human pathogen and is one of the commonest causative agent of Community and Hospital acquired infections. The treatment of Staphylococcus aureus infection has become problematic because of emergence of resistance to Penicillin, Methicillin, Vancomycin and many other antibiotics, by acquiring several resistance mechanisms. Increased antimicrobial resistance for such an organism is, therefore a cause of concern.

In the past few decades MRSA has emerged as an important nosocomial pathogen worldwide. In India, prevalence rate varies from $30-85 \%$ in different parts and has now become endemic (Lowy, 1998). A multicentric study done in India involving 17 tertiary care Hospitals reported MRSA prevalence of $41 \%$ in 2008-2009 (Mallick et al., 2010). MRSA is of serious therapeutic concern not only due to its resistance to Methicillin, but also because of resistance to many other antimicrobials that are used on regular basis in Hospitals. Therefore, the most reliable and sustained therapeutic agent against methicillin-resistant Staphylococcus aureus (MRSA) strains is Vancomycin. Extensive use of this antibiotic inturn lead to the emergence of Vancomycin intermediate Staphylococcus aureus [VISA] and Vancomycin resistant Staphylococcus aureus [VRSA] strains in various parts of the world (Manu et al., 2013).

In the present study a total of 161 nonduplicate Staphylococcus aureus strains were isolated from various clinical specimens. Among all these samples highest isolation was from pus 103 (64\%). Harcharan singh et al., (2014) in Udaipur (65\%), Manu Chaudhary et al., (2013) in H.P (63\%) and Ankur Goyal et al., in Agra (66.03\%), also reported the highest isolation of Staphylococcus aureus from pus.

All the Staphylococcus aureus strains were screened for Methicillin resistance using Cefoxitin disc diffusion method. Since it is a potent inducer of mecA gene, hence considered as a surrogate marker for detection of methicillin resistance by CLSI 2012, in our study $82(51 \%)$ isolates turned out to be MRSA and 79(49\%) as MSSA, from a total of 161 Staphylococcus aureus strains. The prevalence rate of MRSA in our institute is $51 \%$, which is similar to the studies conducted by Vidhani and Mehndiratta et al., in 2001 showing a prevalence rate of $51.6 \%$ and almost comparable to the study conducted by Majumdar et al., in 2001 and Assadullah et al., in 2003 showing $52.9 \%$ prevalence rate. The higher rate in their studies may been attributed to the fact that the studies were conducted at a tertiary care multispecialty center with more and more patients coming from pheriphery and small nursing homes, where injudious use of antibiotics and inadequate infection control policies are prevalent. Verma et al., in 2000 reported a higher prevalence rate of $80.89 \%$ in Indore and Mehta et al., in 2007 reported a lower prevalence rate of $24 \%$ in Chandhigarh. This variation in prevalence may be because of several factors like different Geographical and 
environmental conditions, population group under study, healthcare facilities available in the particular hospital, implementation and monitoring of infection control committee, rationale antibiotic usage which varies from hospital to hospital. We have $51 \%$ prevalence rate of MRSA in our hospital setup. It therefore calls in for better vigilance and implementation of more effective MRSA surveillance programme complemented with improved infection control practices.

In the present study, maximum MRSA were isolated from pus $50(61 \%)$, followed by blood 13(15\%), respiratory secretions 8 (10\%), Swabs and body fluids 4(5\%) each and least from Urine 3(4\%). This pattern correlates with studies conducted by Vidya Pai et al., in 2010 and Nitish Kumar Sharma et al., 2013. This is due to the reason that Staphylococcus aureus accounts for most of the skin and soft tissue infections, septicemia and also respiratory tract infection.

Comparatively MRSA prevalence was more in males $(73 \%)$ than in females $(23 \%)$ in our study. Similar findings was also reported by Rao et al., (2010) and Abhishek Mewar et al., The increased rate of MRSA infections among males could be due to their more outdoor activities, inturn exposing them to contaminated environment and also compared to females, accidental injuries are more common among men.

Most of the MRSA strains were isolated from 21-30 yrs of age group (ie 32\%) and in 51$60 \mathrm{yrs}$ (ie 26\%), indicating MRSA infection is more common in working and old age group. The reason for this may be that younger age group are more involved in outdoor activities inturn exposing them to contaminated environment and in older age group it may be due to waning immunity, hormonal abnormalities and co-morbid conditions. Similar pattern of affected age group was also reported by Ankur Goyal et al., in 2013.
Isolation was more from the IPD patients $(88.8 \%)$ than from the OPD patients $(11.2 \%)$. Among IPD patients, highest prevalence was seen in orthopedics, oncology and surgical wards. Similarly Mallick and Basak reported 84.8\% MRSA from IPD patients, in which maximum strains were isolated from surgical and orthopedics ward. This might be because the patients in these wards are usually with open wounds and are debilitated. They undergo multiple interventions in the hospital which further increases the risk of MRSA infection due to multiple people involvement as well as prolonged stay in the wards. Along with these factors, the patient is usually on multiple antibiotics.

Resistance of MRSA to a wide range of antibiotics is well documented ${ }^{35}$. In the present study antibiotic resistance is significantly more in MRSA strains of Staphylococcus aureus as compared to MSSA strains. Statistically significant difference was observed for Penicillin, Fluoroquinolones, Erthromycin, Clindamycin and Cotrimoxazole. Such similar statistically significant difference between the sensitivity pattern of MRSA and MSSA was also reported by Vidhani et al., (2013), Shilpa Arora et al., (2013) Majumder et al., (2013).

For Penicillin $100 \%$ resistance was observed for MRSA strains in our study and such similar finding was also reported by Gupta et al., (2010), Anupurba et al., The resistance rate of Ciprofloxacin in MRSA strains was high [93\%], consistent with the resistance rate of Pulimood et al., [90\%] and Udaya Shankar et al., [95.8\%]. Our study had also showed high degree of resistance to Erythromycin and Co-trimoxazole. Such high resistance pattern observed for these antibiotics in our study may be due to the differential clonal expansion and indiscriminate empirical use of these drugs. The present study also showed a low level of resistance to Clindamycin, similar to the study conducted by Ankur 
Goyal et al., (2013). This may be due to the antibiotic recycling and the dependence of the clinicians more on beta lactam drugs. In the light of the present study, we would recommend use of Clindamycin for the management of soft tissue infections, with MRSA strains that are sensitive to Clindamycin since it has better soft tissue penetration and no renal dosing adjustments and thus by reserving Vancomycin for life threatening infections.

The association of Multidrug resistance with MRSA adds to the problem and the presence of MDR strains in the Hospital can't be neglected. Several studies are prevailing for Methicillin resistance from India but few have worked on Multi-drug resistance. MRSA strain showing resistance towards $\geq 3$ antibiotics is defined as MDR strain. MDR MRSA strains in our study is $45 \%$, a study conducted by Majumder et al., (2013) reported $23.2 \%$ MDR- MRSA, $32 \%$ by Anupurva et al., and as high as $63.6 \%$ by Rajaduraipandi et al., (2000). The emergence of MDR MRSA infections is worrisome in the present therapeutic scenario, hence a continuous antibiotic surveillance is required for all the Staphylococcus aureus isolates. This inturn will help in formulation of effective antibiotic policies in the health care set-up or else the threat will increase.

In the present study 3\% resistance was observed for Vancomycin by disc diffusion test, Harcharan Singh et al., (2013) conducted a study in Udaipur and observed a higher resistance of $13 \%$ to Vancomycin by using Disc diffusion method only. Similarly Yogesh Kumar Gupta et al., and Ankur Goyal et al., had reported no vancomycin resistance by Disc diffusion in Rajasthan and Agra respectively.

To conclude, the result of our present study indicated high antibiotic resistance to commonly used antibiotics by MRSA isolates. The increase in vancomycin resistance among MRSA and MDR-MRSA and excessive use of antimicrobial agents has worsened the sensitivity. Hence prudent and responsible usage of newer antibiotics is advocated to preserve their continued effectiveness in the management of difficult to treat infections caused by MRSA and VRSA. We should undertake more and more such studies in future to fight against rising menace of antibiotic resistance. Also more research should be done to find better treatment policies, effective and cheaper alternative antibiotics in developing countries like ours. The findings of the studies should be shared with hospital infection control committee to help in the formulation of infection control polices and also antibiotic policies. So that the primary care givers can use antibiotics rationally.

\section{References}

Ankur Goyal, Manish Kumar Diwakar, Suneel Bhooshan, Sapna Goyal, Arti Agrawal. et al. 2013. Prevalence and Antimicrobial Susceptibility Pattern of Methicillinresistant Staphylococcus aureus [MRSA] isolates at a Tertiary Care Hospital in Agra, North India - A systemic annual review. $J$. Dent. Med. Sci. (IOSR-JDMS), 11(6): 8084.

Anupurba, S., Sen, M.R., Nath, G., Sharma, B.M., Gulati, A.K., Mohapatra, T.M. 2003. Prevalence of methicillin resistant Staphylococcus aureus in tertiary referral hospital in Eastern Uttar Pradesh. Indian J. Med. Microbiol., 21(1): 49-51.

Arora, S., Devi, P., Arora, U., Devi, B. 2010. Prevalence of Methicillin- resistant Staphylococcus aureus (MRSA) in a tertiary care hospital in northern India. $J$. Lab Physicians, 2: 78-81.

Assadullah, S., Kakru, D.K., Thoker, M.A., Bhat, F.A., Hussain, N., Shah, A. et al. 2003. Emergence of low level vancomycin 
resistance in MRSA. Indian J. Med. Microbiol., 21: 196-198.

Astagneau, P., and The French Prevalance Survey Study Group, 2000. Prevalence of nosocomial infection in France: results of nationwide survey in 1996. J. Hosp. Infect., 46:186-193

Baird. 1996. Staphylococcus: Cluster-forming gram-positive cocci. In: Collee JG, Fraser AG, Marmion BP, Simmons A, editors. Mackie and McCartney Practical Medical microbiology. 14th edn. Edinburg: Churchill Livingstone. 245-261.

Bandaru Narasinga Rao and Prabhakar, T. 2010. Prevalance and antibiotic susceptibility pattern of Methicillin resistant Staphylococcus aureus [MRSA] in and around Vishkapatnam, A.P. $J$. Pharmaceutical and Scientific Innovation, 4(03).

Barber, M. 1961. Methicillin resistant Staphylococci. J. Clin. Pathol., 4: 385-93.

Boucher, H.W. 2010. Challenges in antiinfective development in the era of bad bugs, no drugs: A regulatory perspective using the example of BSI as an indication, Clin. Infect. Dis., 50: S4-9.

Centers for Disease Control and Prevention. 2002. Staphylococcus aureus resistant to vancomycin -United States, 2002. Morb Mortal Wkly. Rep. MMWR, 51: 565-567.

Clinical and Laboratory Standards Institute [CLSI]. 2012. Performance Standards for Antimicrobial Susceptibility Testing. Twenty- second Informational Supplement. M100-S22, 32(1).

Clinical and Laboratory Standards Institute. Performance standards for antimicrobial susceptibility testing. 2007. 17th informational supplement M100-S17, CLSI, Wayne, PA.

Diep, B.A., Carleton, H.A., Chang, R.F., Sensabaugh, F., Perdreau Remington. Roles of 34 virulence genes in the evolution of hospital and community associated strains of Methicillin resistant Staphylococcus aureus. J. Hosp. Infect., 46: 186-193.

Hafiz, S., Hafiz, A.N, Ali, L., Chughtai, A.S., Memon, B: 2002. Methicillin resistant
Staphylococcus aureus: a multicentre study. JPMA, 52: 312.

Harcharan Singh, Meena Atray, and Pankaj Kumar Modi et al. 2014. Antibiotic susceptibility pattern of Methicillin resistance Staphylococcus aureus in tertiary care center at Southern Rajasthan. IJPSR, 5(2): 607-611.

Koneman Elmer, Winn Washington, Allen Staphen, Procop Gary editors. 2006. Color Atlas \& Textbook of Diagnostic Microbiology, 6th edition, 643-648.

Koneman Elmer, Winn Washington, Allen Staphen, Procop Gary editors. 2006. Color Atlas \& Textbook of Diagnostic Microbiology, 6th edition, $643-648$.

Lowy, F.D. 1998. Staphylococcus aureus infection. N. Engl. J. Med., 339: 520-532.

Majumder, D., Sarma Bordoloi, J.N., Phukan, A.C., et al. 2001. Antimicrobial susceptibility pattern among methicillin resistant Staphylococcus isolates in Assam. Ind. J. Med. Microbiol., 19(3): 21-27.

Mallick, S.K. and Basak, S. 2010. MRSA- too many hurdles to overcome: a study from Central India. Tropical Doctor, 40: 108110.

Manu Chaudhary and Anurag Payasi. 2013. Prevalance of Heterogeneous Glycopeptide intermediate resistance in Methicillin resistant Staphylococcus aureus. American J. Infect. Dis., 9(3): 63-70.

Mehta, A., Rodrigues, C., Kumar, R., et al. 1996. A pilot programme of MRSA surveillance in India (MRSA Surveillance Study group). Postgrad. Med. J., 42(1): 1-3.

Nitish, K., Raina, G., Shrikala, B., and Gopalkrishna, B.K. 2013. Nosocomial Infections and Drug Susceptibility Patterns in Methicillin Sensitive and Methicillin Resistant Staphylococcus aureus. Clin. Diagn. Res., 7: 2178-2180.

Priyanka Chauhan, Prabhakar S. Bais and Nidhi Gupta et al. Prevalance of Methicillin resistant Staphylococcus aureus (mac A gene) among the patients admitted in Intensive care Unit. Int. J. Bioassays, 02(09): 1256-1259. 
Rajaduraipandi, K., Mani, K.R., Panneerselvam, K., et al. 2006. Prevalence and antimicrobial susceptibility pattern of methicillin resistant Staphylococcus aureus: a multicentre study. Indian J. Med. Microbiol., 24: 34-8.

Ratnaraja, N.V., Hawkey, P.M. 2008. Current challenges in treating MRSA: What are the options? Expert Rey Anti-Infect Therapy, 6: 601-18.

Sangeeta Joshi, Pallab Ray, Vikas Manchanda, Jyoti Bajaj, D.S. Chitnis, Vikas Gautam. 2013. Indian network for surveillance of Antimicrobial Resistance (INSAR) Group, India. Methicillin resistant Staphylococcus aureus (MRSA) in India: Prevalence \& susceptibility pattern. Indian J. Med. Res., 137(2): 363-369.

Sangeeta Joshi, Pallab Ray, Vikas Manchanda, Jyoti Bajaj, D.S. Chitnis, Vikas Gautam. 2013. Indian network for surveillance of Antimicrobial Resistance (INSAR) Group, India. Methicillin resistant Staphylococcus aureus (MRSA) in India: Prevalence \& susceptibility pattern. Indian J. Med. Res., 137(2): 363- 369.

Sharma, Prajna; Vishwanath, G., et al. 2012. Study of vancomycin susceptibility in methicillin-resistant Staphylococcus aureus isolated from clinical samples. Annuals of Trop. Med. Public Health, 5(3): 178-180.

Verma, S., Joshi, S., Chitnis, V., et al. 2000. Growing problem of Methicillin resistant Staphylococci: Indian Scenario. Ind. $J$. Med. Sci., 54(12): 535-40.

Vidhani, S., Mathur, M.D., Mehndiratta, P.L., Rizvi, M. 2003. Methicillin resistant Staphylococcus aureus: the associated risk factors. Indian J. Pathol. Microbiol., 46(4): 676-679.

Vidya Pai, Venkatakrishna, I., Rao, Sunil, P. Rao. 2010. Prevalence and Antimicrobial Susceptibility Pattern of Methicillinresistant Staphylococcus Aureus [MRSA] Isolates at a Tertiary Care Hospital in Mangalore, South India. J. Lab. Physicians, 2(2): 82-4.

Waldvogel, F.A. 2000. Staphylococcus aureus. Mandell GL, BennettJE, Dolun R, Churchis Livingstone editors. In principles and practice of infectious diseases. Philadelphia Pennsyl vania USA., 2069-2092.

Yogesh Kumar Gupta, Garima gupta, S.P. Garg, Prem Singh nirwan, et al. 2013. Prevalence and antimicrobial susceptibility pateern of Methicillin resistant Staphylococcus aureus isolated at a tertiary care institute in North West Region of Rajasthan. Int. Res. J. Pharmaceutical and Appl. Sci., (6): 13-16.

\section{How to cite this article:}

Anjali Kulshrestha, V. Anamika, K. Mrithunjay, V. Himanshu, K. Manish and Dalal, A.S. 2017. A Prospective Study on the Prevalence and Antibiotic Sensitivity Pattern of Methicillin Resistant Staphylococcus aureus isolated from Various Clinical Specimen at a Tertiary Care Post Graduate Teaching Institute. Int.J.Curr.Microbiol.App.Sci. 6(3): 1859-1869.

doi: https://doi.org/10.20546/ijcmas.2017.603.212 